\title{
ARTICLE
}

\section{The migration experiment of Sr-90 in variable saturated soils and numerical simulation used Hydrus-3d}

\author{
Anchang Deng, Jun Zhu, Yunfeng Shi, Chao Chen, Tian Xie, Ting Li and Aiming Zhang* \\ China Institute of Radiation Protection, Taiyuan 275-93, 030006, China
}

\begin{abstract}
There is a scientific support that migration data of Sr-90 in the nuclear waste landfill soil will provide for safety estimation and accident response measures in landfill.In order to make a more accurate prediction of the migration of $\mathrm{Sr}-90$, it is critical to get the migration parameters such as longitudinal (or transverse) dispersivity and partition coefficient. This article try to use a method for estimating the migration parameters of Sr-90 in variable saturated soils combining experiment and numerical simulation, then explores the method with the migration of Sr-90 in silty loam in Shanxi province as an example. The migration experiment of Sr-90 was carried by column method, the water flow in is $375 \mathrm{~mL} / \mathrm{d}$, the $\mathrm{pH}$ value was about 7 at room temperature. The results show that the migration distance of central flow direction for $\mathrm{Sr}-90$ is $3.9 \mathrm{~cm}$ and the peak concentration is $1.04 \times 10^{4} \mathrm{~Bq} / \mathrm{cm}^{3}$. According to the concentration distribution of Sr-90 in the soil column combined with three-dimensional numerical model of nuclide migration (Hydrus-3d), the partition coefficient in the silty loam is $79 \mathrm{ml} / \mathrm{g}$ while the longitudinal dispersivity is $0.7 \mathrm{~cm}$ and the transverse dispersivity is $0.8 \mathrm{~cm}$ by fitting. This method takes the porosity and water velocity of solid into consideration that static experiments fail to cover and obtains the longitudinal and transverse dispersivity at the same time, which making the results more tally with the actual situation.
\end{abstract}

Keywords: Sr-90; saturated - unsaturated soils; solute migration; dispersivity; partition coefficient

\section{Introduction}

As a special kind of solute, the migration of Sr-90 in soil has not only the typical characteristics of other normal solutes, including convection, dispersion, adsorption, decay, biodegradation etc., but also has particularity--- the delayed effect caused by adsorption function receives more consideration. The accurate description of the migration of $\mathrm{Sr}-90$ in soil depends on two key parameters: the hydrodynamic dispersion and the partition coefficient that reflects adsorptive characters. At present, the calculation of partition coefficient mainly uses the static adsorptive experiment by which the Sr-90 is put into a solution whose solid-to-liquid ratio is known and the ratio of these two is the partition coefficient after the concentration of solid and liquid levels out. However, the static method ignores the influence of porosity and flow velocity in the solid and liquild. The hydrodynamic dispersion is usually calculated by soil column method, but the longitudinal dispersivity can only be gotten based on the penetration curve of tracer and the longitudinal and transverse dispersion can barely gotten by using the three-dimensional model [1-7]. In order to get more reasonable partition coefficient of $\mathrm{Sr}-90$ and calculate

*Corresponding author: Email: shuigong@cirp.org.cn the hydrodynamic dispersion at the same time, this experiment employs the $\mathrm{Sr}-90$ as the tracer. First, to establish three-dimensional soil column physical experiment and then the partition coefficient and hydrodynamic dispersion of Sr-90 are gotten by building the three-dimensional saturated-unstaurated zone numerical migration model with Hydrus-3d software based on the longitudinal and transverse concentration distribution of Sr-90 in the soil column.

\section{The materials and methods of the migration experiment}

\subsection{Materials}

The soil sample is from Yuci, Shanxi province and the texture is silty. The percentage of sand, silt and clay are $25.5 \%, 64 \%, 10.5 \%$ respectively with bulk density $1.35 \mathrm{~cm}^{3} / \mathrm{g}$. Among the mineral composition, the content of quartz is $30 \sim 35 \%$, mica $10 \%$, plagioclase $15 \sim 20 \%$, potassium feldspar $8 \%$, chlorite $8 \%$, hornblende $3 \%$, calcite $15 \sim 20 \%$ and kaolinite 3\%.

Tracer: $\mathrm{Sr}-90$ in $\mathrm{SrCl}_{2}, 1.535 \times 10^{6} \mathrm{~Bq}, 1 \mathrm{ml}$ solution mixed with $160 \mathrm{~g}$ quartz sand

Measuring instrument: HPGe $\gamma$ Spectrometer (OTREC company), the range of energy response 40 $\mathrm{KeV}-10 \mathrm{MeV}$, energy resolution less than $1.8 \mathrm{KeV}$ 
(1.332 MeV).

Sr-90 was measured with bremsstrahlung spectra.

\subsection{Experimental facility}

The experimental device consists of 3 parts: (1)the water supply facility, including water box and peristaltic pump used to control the flow; (2)the soil column facility; (3)the collection of effluent facility, as shown in Figure 1.

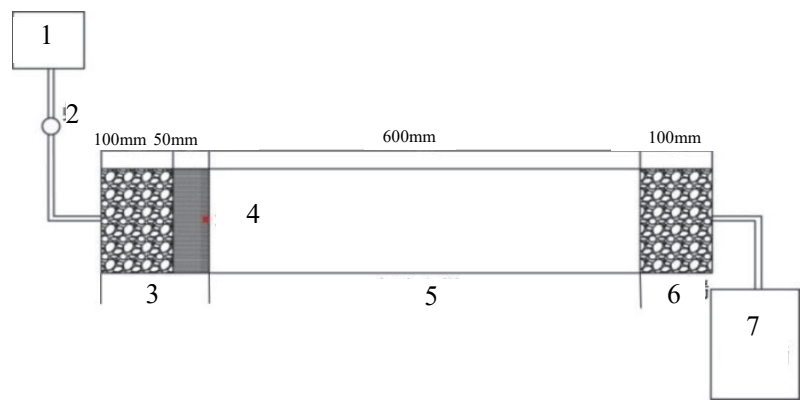

1. Water box ; 2. Peristaltic pump; 3. Water entry; 4 Tracer; 5. Soil sample 6. water exit; 7.waste liquid collection barrel

Figure 1. Soil column experiment device.

The material of soil column is PMMA(polymethyl methacrylate) and the thickness is $1.0 \mathrm{~cm}$. The size of experiment box is $850 \mathrm{~mm} \times 150 \mathrm{~mm} \times 150 \mathrm{~mm}$. The experiment box has 4 parts: water entry, tracer, soil sample and water exit. The length of water entry is $150 \mathrm{~mm}$ and filled with $100 \mathrm{~mm}$ coarse sand and $50 \mathrm{~mm}$ quartz sand ( 80 mesh) in turn. The tracer(Sr-90 in quartz sand) had been put in the soil which in the junction of water entry. The location seen in Figure 1 , No. 4 . The length of experiment soil sample taken from silt soil in Yuci is $600 \mathrm{~mm}$. The length of water exit filled with coarse sand is $100 \mathrm{~mm}$. The water entry is connected to peristaltic pump and the flow is $375 \mathrm{~mL} / \mathrm{d}$ (according to the real flow velocity). Distilled water is used in this experiment. The water exit is connected to waste liquid collection barrel and the volume of flow liquid is measured daily. The $\mathrm{pH}$ value is consistent with the $\mathrm{pH}$ value of the experimental soil environment, which is about 7 . The experiment had been carried out at room temperature.

\subsection{Disintegration and Measurement}

The experiment lasts for 260 days and water supply is ensured during this period. In order to get the longitudinal dispersivity, the tracer point (the junction of water entry and experimental soil sample) is set as zero and the direction of water flow as positive. The soil column is put into slices with each $3 \mathrm{~mm}$ in thickness and $7.8 \mathrm{~cm}$ long. As to the transverse dispersivity, The cutting ring put every slice into 4 soil sample circles with radius $1 \mathrm{~cm}, 3 \mathrm{~cm}, 5 \mathrm{~cm}$ and $7 \mathrm{~cm}$ separately. There are 7 regions with two-layer (except the $1 \mathrm{~cm}$ radius one) (Figure 2) and 182 soil samples. The samples are put into the polyethylene box and then dried, weighed, and finally the concentration of $\mathrm{Sr}-90$ is measured.

\subsection{The measurement of soil hydraulic parameters}

Soil hydraulic parameters include soil water characteristic curve and saturated hydraulic conductivity. The measure of soil water characteristic curve uses the sand funnel method and mechanical strain method. The sand funnel method is used when the absorption force of soil is less while the mechanical strain method is used when the soil has great absorption. The absorption value with different volume water content is measured. The saturated water content $\theta_{s}$ is $0.445 \mathrm{~cm}^{3} / \mathrm{cm}^{3}$ and the residual water content $\theta_{r}$ is $0.046 \mathrm{~cm}^{3} / \mathrm{cm}^{3}$ by using the Van Genuchten(1980)model. The reciprocal value of air admission $\alpha$ is 0.00464 and $n$ is 3.20 . In addition, the saturated hydraulic conductivity of silt soil is $2.26 \times 10^{-5}$ $\mathrm{cm} / \mathrm{s}$ by constant head method.

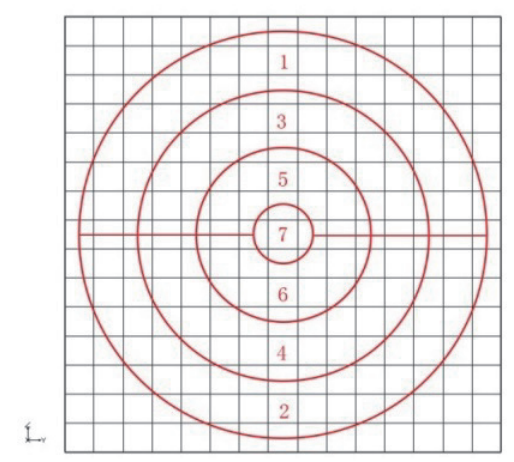

Figure 2. Sampling schematic.

\section{Results of the migration experiment}

The longitudinal concentration distribution curves of Sr-90 in each region are obtained from this experiment. The peak concentration is shown in Table 1. The concentration distribution curves of Sr-90 in each region show the unimodality in normal distribution and the concentration peaks of the curves only move down by $2.7 \sim 3.9 \mathrm{~cm}$, which means silty loam has strong absorption to Sr-90. Its migration principle can be described through equilibrium adsorption theory [8-11], i.e. Sr-90 in the silty loam can easily get to adsorption and desorption equilibrium and the concentration of Sr-90 in the solid is the product of partition coefficient and liquid concentration at this moment.

\section{Parameter solution}

\subsection{Method of parameter solution}

In order to solve the migration parameters, including hydrodynamic dispersivity and partition coefficient, the three-dimensional numerical simulation method must be used. The method is described as follows: the measured concentration distribution curve of Sr-90 is obtained in each region according to the measured concentration distribution along the longitudinal direction in these 7 
regions and the concentration value are regarded as validation data.

The three-dimensional variable saturated soil solute transport numerical model based on equilibrium absorption mode is applied in terms of the results of the experiment lasting for 260 days. The concentration distribution curve of $\mathrm{Sr}-90$ is obtained by plotting along the longitudinal direction in 7 regions. The analysis is made by comparing the measured distribution curve and calculated distribution curve. According to the level of fitting, the partition coefficient $K_{d}$, the longitudinal dispersivity $D_{L}$ and transverse dispersivity $D_{H}$ in the silt loam are worked out.

Table 1. Peak concentration distribution of ${ }^{90} \mathrm{Sr}$.

\begin{tabular}{ccc}
\hline Regions & $\begin{array}{c}\text { Peak migration } \\
\text { distance } \\
(\mathrm{cm})\end{array}$ & $\begin{array}{c}\text { Peak } \\
\text { concentration }(\mathrm{Bq} \\
\left.\mathrm{cm}^{-3}\right)\end{array}$ \\
\hline 1 & 2.7 & $1.12 \times 10^{3}$ \\
2 & 3.3 & $1.86 \times 10^{3}$ \\
3 & 3.6 & $2.00 \times 10^{3}$ \\
4 & 3.6 & $4.04 \times 10^{3}$ \\
5 & 3.6 & $8.03 \times 10^{3}$ \\
6 & 3.6 & $9.80 \times 10^{3}$ \\
7 & 3.9 & $1.04 \times 10^{4}$ \\
\hline
\end{tabular}

\subsection{Verfication of flow}

Before establishing the numerical migration model of saturated-unsaturated flow, it is necessary to construct the flow model and get the measured data used for verification of flow. The tracer is set as initial point and the piezometer tubes are laid along flow direction every $15 \mathrm{~cm}$ which are used to measure the distribution of water head along axial direction (Figure 3). Two piezometer tubes are laid around $2 \#$ up and down (5\# and 6\#) and the interval is $6 \mathrm{~cm}$ which can measure the distribution of water head along radial direction.

\subsection{Numerical simulation model}

The variable saturated soils three-dimensional flow model is established by Hydrus-3d after acquiring the distribution of water head in the soil column. The soil column is put into $3 \mathrm{~mm}$ rectangle cell along the flow direction in the model space and $10 \mathrm{~mm}$ rectangle cell in the $\mathrm{y}$ and $\mathrm{z}$ direction. The size of the cell is $3 \mathrm{~mm} \times 10$ $\mathrm{mm} \times 10 \mathrm{~mm}$ and subdivided into 15 layers, 15 lines and 283 rows. Thus there are 72704 nodes and 127350 grids. The accuracy of established flow model is verified according to the measured head water value (Table 2). Figure 4 shows the distribution of water head calculated in the experiment box.

\subsection{Results of numerical simulation}

The measured water head value and calculated value are basically consistent by comparison and the established model reveals the real condition of the flow in the box. The value of hydraulic gradient $\mathrm{J}$ is 1.10 which is calculated with the difference of the two water head and $\Delta \mathrm{x}$. The osmotic coefficient of the soil column is $1.76 \times 10^{-5} \mathrm{~cm} / \mathrm{s}$ by using the Darcy Formula and the result is basically coincident with measured value of water head.

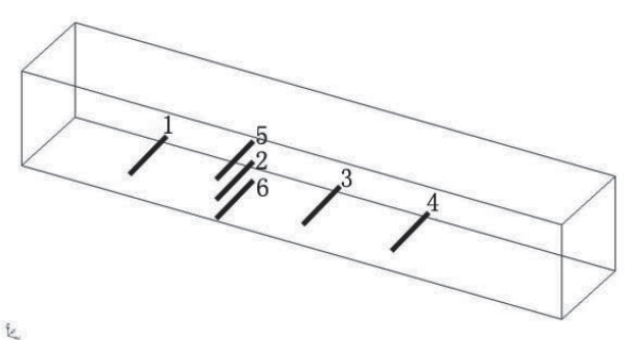

Figure 3. Piezometer tubes distribution.

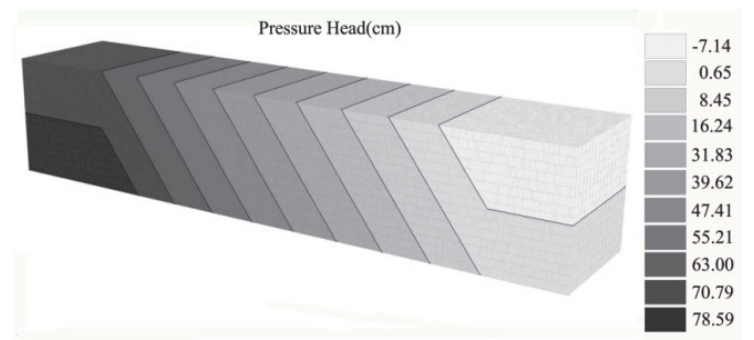

Figure 4. Calculation of water head distribution.

Table 2. Results of measured values and calculated values.

\begin{tabular}{cccccccc}
\hline $\begin{array}{c}\text { Piezometer } \\
\text { tubes } \\
\text { position }\end{array}$ & NO. & 1 & 2 & 3 & 4 & 5 & 6 \\
\hline Coordinate $\begin{array}{c}\mathrm{x} \\
(\mathrm{cm}) \\
\mathrm{z}\end{array}$ & 0 & 15 & 30 & 45 & 15 & 15 \\
$(\mathrm{~cm})$ & & 8 & 8 & 8 & 2 & 14 \\
\hline Measured water & 61. & 47. & 44. & 13. & 52. & 44. \\
head/(cm) & 23 & 85 & 40 & 67 & 00 & 12 \\
Calculated water & 70. & 53. & 35. & 17. & 59. & 47. \\
head $/(\mathrm{cm})$ & 56 & 06 & 21 & 36 & 06 & 06 \\
\hline
\end{tabular}

\section{5. parameter solution}

It is considered that the concentration of Sr-90 in solid is the product of partition coefficient and liquid concentration on the basis of equilibrium adsorption theory after the establish and verification of the flow model. The three-dimensional model of saturated-unsaturated flow migration is set up by Richards formula based on equilibrium adsorption mode according to the concentration distribution of Sr-90 in the axial and radial direction. The mathematical expression as Eq. (1).

$$
\left\{\begin{array}{l}
\theta \frac{\partial \mathrm{C}}{\partial t}=\frac{\partial}{x_{i}}\left(\theta D_{i j} \frac{\partial C}{\partial x_{j}}\right)-\frac{\partial}{\partial x_{i}}\left(q_{i} C\right)-\rho_{b} \frac{\partial S^{k}}{\partial C} \\
\frac{\partial S^{k}}{\partial t}=K_{d} \frac{\partial c}{\partial t}
\end{array}\right.
$$

In this expression, $\theta$ is volume moisture content, $\mathrm{cm}^{3} / \mathrm{cm}^{3} ; t$ is the migration time of solute, $\mathrm{d} ; q_{i}$ is Darcy 
flow rate, $\mathrm{cm} / \mathrm{d} ; D_{i j}$ is dispersion coefficient, $\mathrm{cm}^{2} / \mathrm{d} ; \rho$ is volume dry density, $\mathrm{g} / \mathrm{cm}^{3} ; C$ is concentration of dissolved phase, $\mathrm{Bq} / \mathrm{cm}^{3} ; S^{k}$ is concentration of adsorbed phase, $\mathrm{Bq} / \mathrm{cm}^{3} ; K_{d}$ is partition coefficient under the equilibrium adsorption, $\mathrm{cm}^{3} / \mathrm{g}$.

The concentration of $\mathrm{Sr}-90$ in the whole box is obtained through the model calculation. The model in the horizontal direction is divided into 15 layers from bottom up and the concentration of Sr-90 in 7 layers $(2,4,6,8,10,12,14)$ are selected (see Figure 5). The calculated results are consistent with the measured ones. The maximum value is the 8 th layer(the center one) and the value decreases away from center along up and down. While the concentration in bottom half is greater than that of upper half at the symmetrical part. Sr-90 has

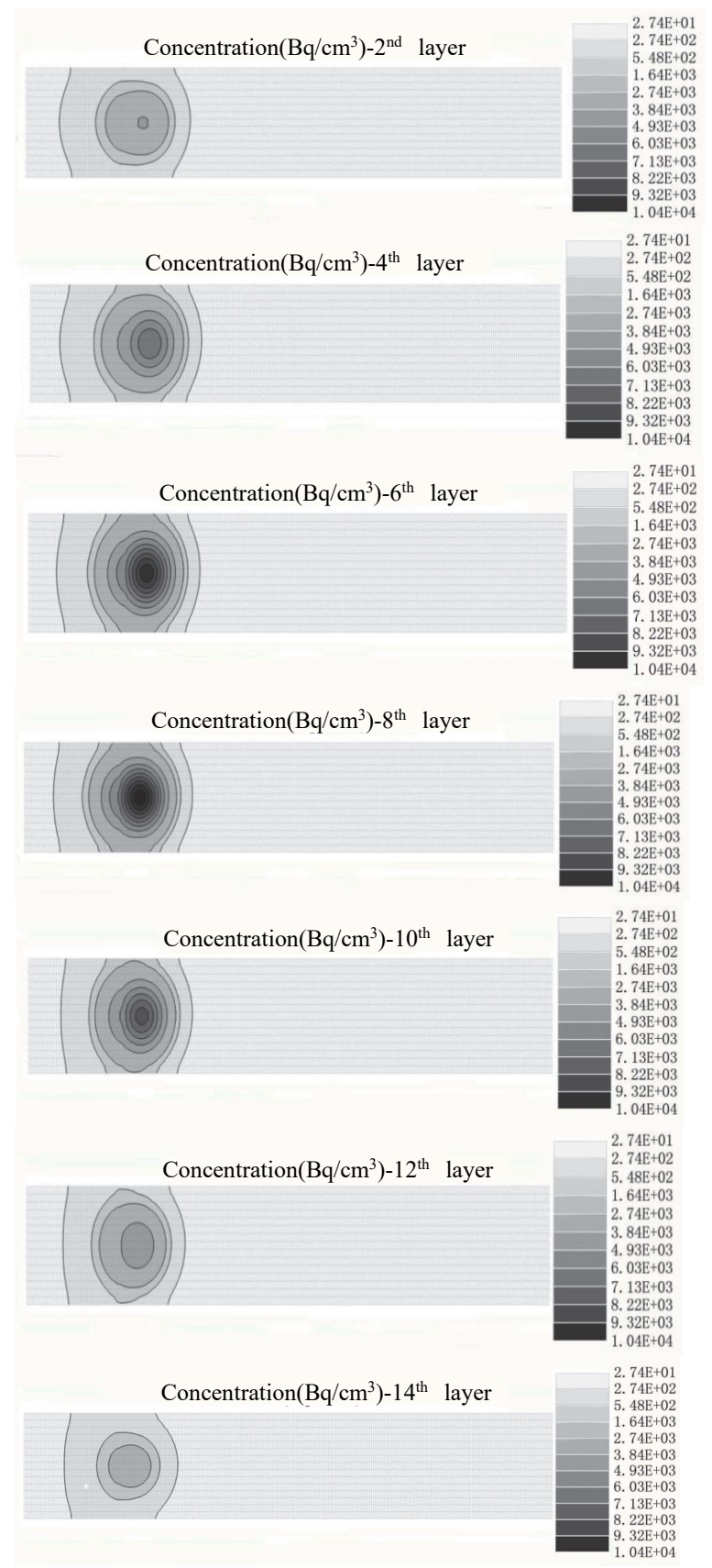

Figure 5. Calculated concentration of hydrus-3d. already migrated from center to top and bottom during the 260 days, which reveals the transverse dispersivity is the key of the radial migration of Sr-90.

The curve of calculated concentration distribution is obtained by plotting the concentration of $\mathrm{Sr}-90$ in each region (1-7) along longitudinal direction. A comparison is made between the measured distribution curve and the calculated curve by numerical model.

The parameter fitting results are shown in Figure 6. It shows the good agreement of numerical and the experimental results. The partition coefficient of Sr-90 in the silt loam at Yuci, Shanxi is $79 \mathrm{ml} / \mathrm{g}$, the results take the porosity of solid and flow velocity into fully consideration with the comparison of the static adsorption experiment, thus tallying with the actual condition. The longitudinal dispersivity $D_{L}$ is $0.7 \mathrm{~cm}$ and the transverse dispercity is $0.8 \mathrm{~cm}$. These two values are consistent which indicates they are isotropic.

The silt loam of this experiment is from field testing ground in Yuci of CIRP. In the 1990s, Jinsheng Wang [12] et al. made the in-situ experiment of Sr-85 migration in the silt loam at this field and acquired the partition coefficient $71.18 \mathrm{ml} / \mathrm{g}$, longitudinal dispersivity $D_{L}$ is $0.915 \mathrm{~cm}$ and the transverse dispercity is $0.55 \mathrm{~cm}$. Sr-85 and Sr-90 are isotopes and they have same chemical property. The calculated results are consistent with the data of the field experiment, so this method can be used to obtain the key migration parameters of Sr-90 in soil.

\section{Conclusion}

This paper analyzed the establishment of the saturated-unsaturated flow physical experiment model and the migration principle of Sr-90 in the silt loam through the three-dimensional soil column experiment combined with numerical simulation method as well. The results indicate that the migration principle accords with the equilibrium adsorption and the key migration parameters (partition coefficient, hydrodynamic dispersivity) were obtained according to the concentration migration curve. This method breaks through the limitations of the traditional static adsorption experiment which ignores the porosity of solid and the water velocity, thus make the results more tally with actual condition. In addition, the longitudinal dispersivity and transverse dispersivity obtained at the same time fill the gap of only getting the longitudinal dispersivity before, which offers a solving method to accurately predict the migration of $\mathrm{Sr}-90$ in soil at nuclear waste landfill. 

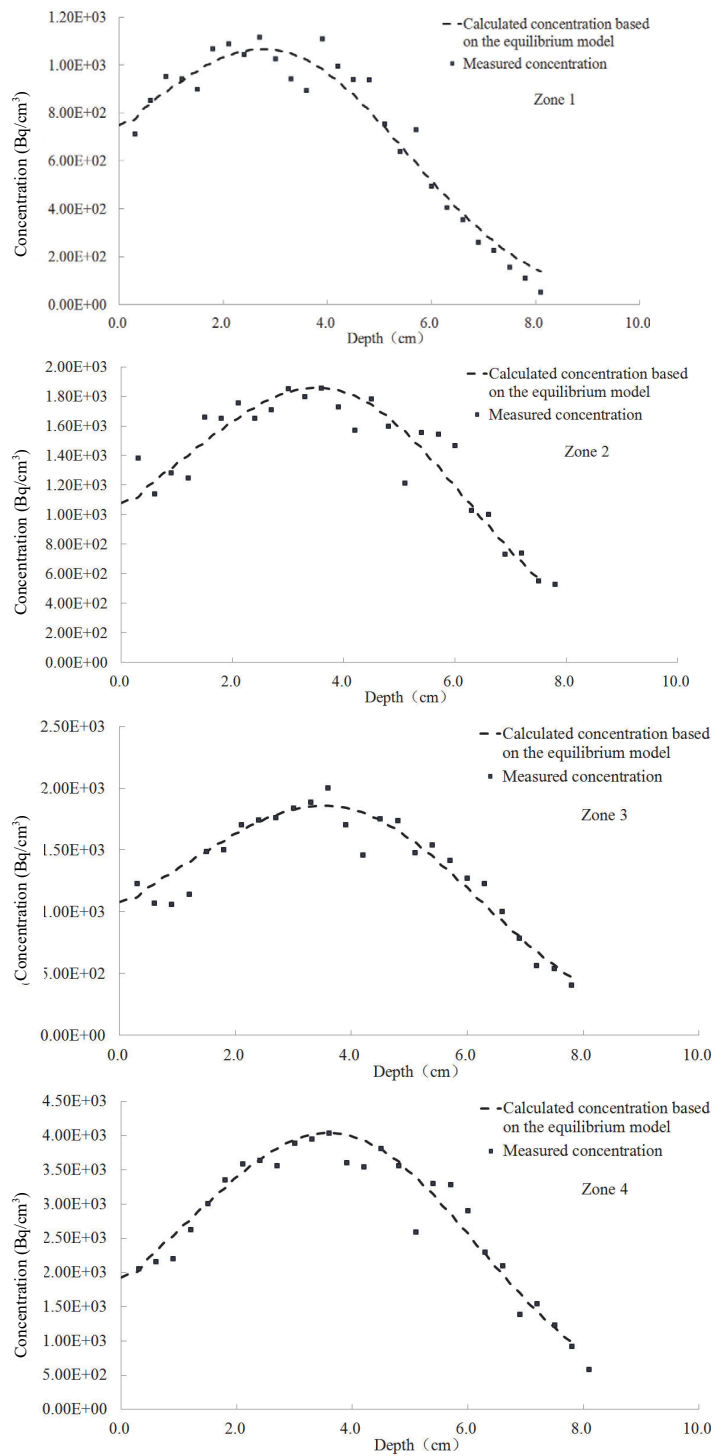

Figure 6. Fitting of measured and calculated value.

\section{References}

[1] C. Liu, J. Yang, X.-B. Chen and R. Yao, Hydrodynamic dispersion coefficient of saturated-unsaturated soil in shihezi irrigation areas, J. Journal of Irrigation and Drainage, 27 (2008), pp. 39-42.

[2] F. Zhang, S. Kang and Y. Pan, Experimental study on hydrodynamic dispersion of adsorption solute in saturated-unsaturated soil, J. Journal of Hydraulic Engineering, 3 (2002), pp. 84-90.

[3] C. Li and Y. Qin, The mathematical model and application of nudide migration in the saturated-unsaturated 3D flow field, J. Journal of China Agricultural University, 2 (1997), pp. 44-49.

[4] X. Zeng, L. Zhan, X. Zhong and Y. Chen, Similarity of centrifuge modeling of chloride dispersion in low-permeability clay, J. Journal of Zhejiang University (Engineering Science), 50 (2016), pp. 241-249.

[5] M. Ma, J. Wang, Z. Guo and C. Cai, Research on sediment and solute transport on red soil slope
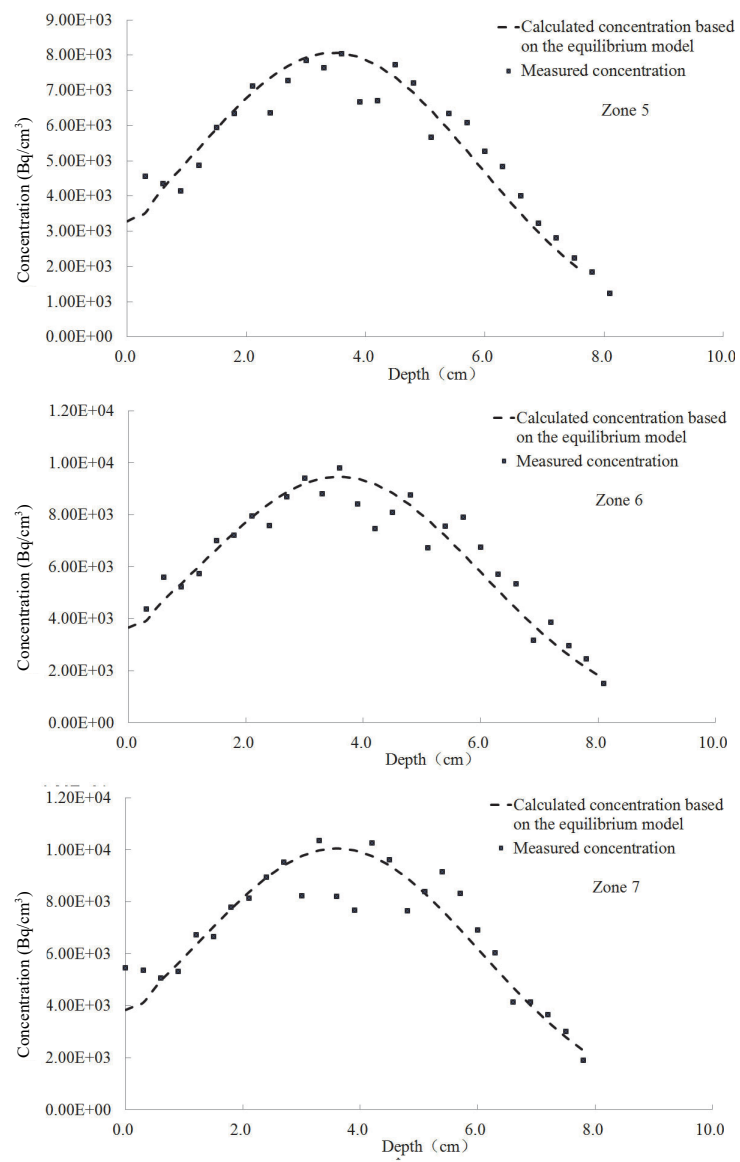

under simultaneous influence of scouring flow, $J$. Acta Pedologica Sinica, 53 (2016), pp. 365-374.

[6] S. Li, S. Bai, Y. Yang and S. Li, Numerical simulation of nitrate nitrogen migration in soil with water table fluctuation, J. Chinese Journal of Soil Science, 45 (2014), pp. 1077-1082.

[7] L. Jiang and B. Liang, A coupled model of hydro-transport in variable saturated porous media considering geochemical process, J. Journal of Jilin University (Earth Science Edition), 41 (2011), pp. 1529-1534.

[8] G. Yu, J.-S. Huang and Z. Gao, Study on water and salt transportation of different irrigation modes by the simulation of HYDRUS model, J. Journal of Hydraulic Engineering, 44 (2013), pp. 826-834.

[9] W.J. Cho, J.O. Lee and H.J. Choi, Radionuclide migration through an unsaturated clay buffer under thermal and hydraulic gradients for a nuclear waste repository, J. Annals of Nuclear Energy, 50 (2012), pp. 71-81.

[10]R. Merk, Numerical modeling of the radionuclide 
Progress in Nuclear Science and Technology, Volume 6, 2019

water pathway with HYDRUS and comparison with the IAEA model of SR 44, J. Journal of Environmental Radioactivity, 105 (2012), pp. 60-69.

[11]L. Yifei, T. Shuaihui and Q. Tianwei, Transport and retention of strontium in surface-modified quartz sand with different wettability, J. Journal of
Radioanalytical and Nuclear Chemistry, 289 (2011), pp. 337-343.

[12]J. Wang, S. Li, Z. Wang and Z. Guo, Two-dimensional nonequilibrium sorption numerical model of radionuclide migration, $J$. Chinese Journal of Applied Ecology, 7 (1996), pp. 89-93. 